\title{
Deterioration of Concrete by the Oxidation of Sulphide Minerals in the Aggregate
}

\author{
Josée Duchesne and Benoît Fournier \\ Department of Geology and Geological Engineering, Université Laval, Québec G1Y 2S4, Canada
}

\begin{abstract}
Cases of degradation of concrete associated to iron sulphides in aggregates were recently recognized in the Trois-Rivières area, Canada. The aggregate used to produce concrete was an anorthositic gabbro containing various proportions of pyrite, pyrrhotite, chalcopyrite and pentlandite. Quantitative microanalysis on sulphide minerals show that pyrrhotite contains small amount of Ni, Co, $\mathrm{Cu}$ and As substituting for $\mathrm{Fe}$ in the mineral structure. Considering element substitution, $x$ value in the chemical formula $\left(\mathrm{Fe}_{1-\mathrm{x}} \mathrm{S}\right)$ was calculated to 0.099 in the pyrrhotite studied. Petrographic examination of damaged concretes showed the presence of oxidized pyrrhotite. The observation of polished samples shows, in several cases, that the pyrite is intact while the pyrrhotite presents evident signs of oxidation. In the presence of water and oxygen, pyrrhotite oxidizes to form iron oxyhydroxides and sulphuric acid. The acid then reacts with the phases of the cement paste and provokes the formation of gypsum and ettringite. These minerals were observed by SEM-EDS (scanning electron microscope/energy dispersive $\mathrm{x}$-ray spectrometer) and their precipitation causes a volume increase that creates expansion and cracking of the concrete.
\end{abstract}

Key words: Sulphide minerals, oxidation, expansion, petrographic examination, concrete durability.

\section{Introduction}

Over the past few years, rapid deterioration of concrete foundations occurred in a few housing developments in the Trois-Rivières area (Québec, Canada) two to four years after construction. More than 400 residential owners have faced serious issues related to the deterioration of their concrete foundations and slabs. In some cases, the deterioration was such that immediate remedial actions were required.

The distressed concretes display map cracking on the surface of the walls. A large number of concrete samples were investigated. In all cases, the aggregate material used for the concrete manufacturing was an intrusive igneous rock, more precisely an anorthositic gabbro, containing various proportions of sulphide minerals mostly pyrite $\left(\mathrm{FeS}_{2}\right)$ and pyrrhotite which is a non-stoichiometric mineral of general formula $\mathrm{Fe}_{1-\mathrm{x}} \mathrm{S}$, with $x$ varying from 0 to 0.125 [1-3]. A

Corresponding author: Josée Duchesne, Ph.D., professor, research field: concrete durability. E-mail: Josee.Duchesne@ggl.ulaval.ca. deleterious process involving the oxidation of sulphide minerals is thought to have caused the swelling and cracking of the affected concrete elements.

This study reports the results of site inspections along with concrete cores characterisation using different petrographic tools including stereomicroscope, polarizing microscope, SEM (scanning electron microscope) and EPMA (electron probe micro-analyser). The goal of that study is to present a detailed characterization of the materials in order to reach a better understanding of the mechanisms involved. The next step will be the establishment of a performance test enabling to reliably screen aggregates that can cause deleterious expansion/cracking due to oxidation in concrete.

\section{Materials and Methods}

\subsection{General}

The diagnosis of any concrete deterioration starts with visual site inspection. Visual inspection of 
concrete foundations will include the identification of any evidence of deformation, cracking (pattern and intensity), exposure conditions including water drainage, etc.. Visual inspection also helps selecting sampling locations. Concrete samples (100-mm diameter cores) were drilled through the foundation walls for petrographic examination. Concrete cores were examined for any sign of deterioration and some cores were selected for further testing.

\subsection{Materials}

Crushed coarse aggregates were sampled directly from selected stockpiles at the St-Boniface quarry North of Trois-Rivieres, Québec, Canada. Concrete cores were drilled in different housing foundation walls in the Trois-Rivières area. Crushed aggregates were examined as they are and on polished sections. Concrete cores were cut or broken for megascopic and microscopic examinations.

\subsection{Methods for Assessment and Analysis}

\section{(1) General}

First, concrete cores were cut with a diamond blade. Some surfaces were polished for stereomicroscope observations. Selected sub-samples were impregnated under vacuum with low viscosity resin (Epofix resin, Struers) and polished for polarizing petrography ( $\mathrm{SiC}$ and loose alumina abrasive powders) [4]. To avoid damage to the concrete during preparation, sections were prepared with isopropyl alcohol as a lubricant and excessive heating was avoided. Some concrete pieces were broken in a random way for megascopic examination and SEM observations. Polished samples were carbon coated for EPMA and broken pieces were coated with Au-Pd for SEM observations. Prior to SEM observations, concrete samples were heated in an oven kept at $40{ }^{\circ} \mathrm{C}$ for a minimum of $24 \mathrm{~h}$;

\section{(2) EPMA and SEM}

Polished sections were analysed in a CAMECA SX-100 microprobe equipped with five WDS (wavelength-dispersive spectroscopy) detectors (LIF (lithium fluoride), TAP (thallium acid phthalate), PET (pentaerythritol)) and one PGT (princeton gamma tech) prism EDS detector. Operating conditions were set at $15 \mathrm{kV}$ and 20 (observation) or $30 \mathrm{nA}$ (analysis), at high vacuum $\left(<10^{-5}\right.$ Torr). The instrument was calibrated using a range of mineral standards, and resulting detection limits are on the order of $0.02 \mathrm{wt} \%$. Standards were chosen based on their chemical composition to be as close as phases analysed to avoid matrix effect.

Concrete samples were observed under a JEOL JSM-840A scanning electron microscope equipped with an EDXA (energy dispersive x-ray analysis) system. Operating conditions were set at $15 \mathrm{kV}$. Images were taken in secondary electron mode.

\section{Results}

\subsection{Visual Inspection}

The deteriorated concrete displayed map cracking on the walls with open cracks more pronounced at the corners of the foundation walls (Fig. 1). Crack openings often reach up to $10 \mathrm{~mm}$ and values as high as $40 \mathrm{~mm}$ were reported. Major cracks are often concentrated next to rain gutters, which highlight the role of water or humidity in the reaction and deterioration processes. Yellowish coloration was often seen on the foundation walls. At some locations, iron oxide was visible in the open cracks. Deterioration causes an important breakdown of concrete structures and many foundations had to be replaced (Fig. 2). All the masonry and covering stones were first removed to lighten the structure. Houses were lifted up from their foundations and the later was demolished and replaced. The remediation cost was estimated to be close to the construction cost.

\subsection{Petrographic Examination}

Several samples of damaged concrete observed under a stereomicroscope and a polarizing microscope showed that the altered concretes were all made with 
the same coarse aggregate containing a certain amount of sulphide minerals. The aggregate used to produce the deleterious concrete foundations was an anorthositic gabbro containing various proportions of sulphide minerals including pyrite, pyrrhotite, pentlandite $\left((\mathrm{Fe}, \mathrm{Ni})_{9} \mathrm{~S}_{8}\right)$ and chalcopyrite $\left(\mathrm{CuFeS}_{2}\right)$. Other constituting minerals consist mainly of calcic plagioclase feldspars $\left(\mathrm{CaAl}_{2} \mathrm{Si}_{2} \mathrm{O}_{8}\right)$, with lesser amounts of biotite $\left(\mathrm{K}(\mathrm{Mg}, \mathrm{Fe})_{3} \mathrm{AlSi}_{3} \mathrm{O}_{10}(\mathrm{~F}, \mathrm{OH})_{2}\right)$ and pyroxene $\left(\mathrm{XY}(\mathrm{Si}, \mathrm{Al})_{2} \mathrm{O}_{6}\right.$ - Ca-rich, Na-poor, high-Mg clinopyroxene) (Fig. 3).

The pyrite and pyrrhotite contents vary significantly from one particle to another and can reach up to $5 \%-7 \%$ of the total coarse aggregate volume (Fig. 4).

The megascopic examination of concrete samples showed alteration on pyrrhotite surfaces. Surfaces were light brown and often covered by rust. Some aggregates were completely disintegrated. The bond between the aggregate particles and the cement paste was often weak. The pyrite surface was unaltered even if some particles were directly in contact with particles of pyrrhotite.

Fig. 5 presents reflected light microscopy images of the aggregate where iron sulphides, pyrite and

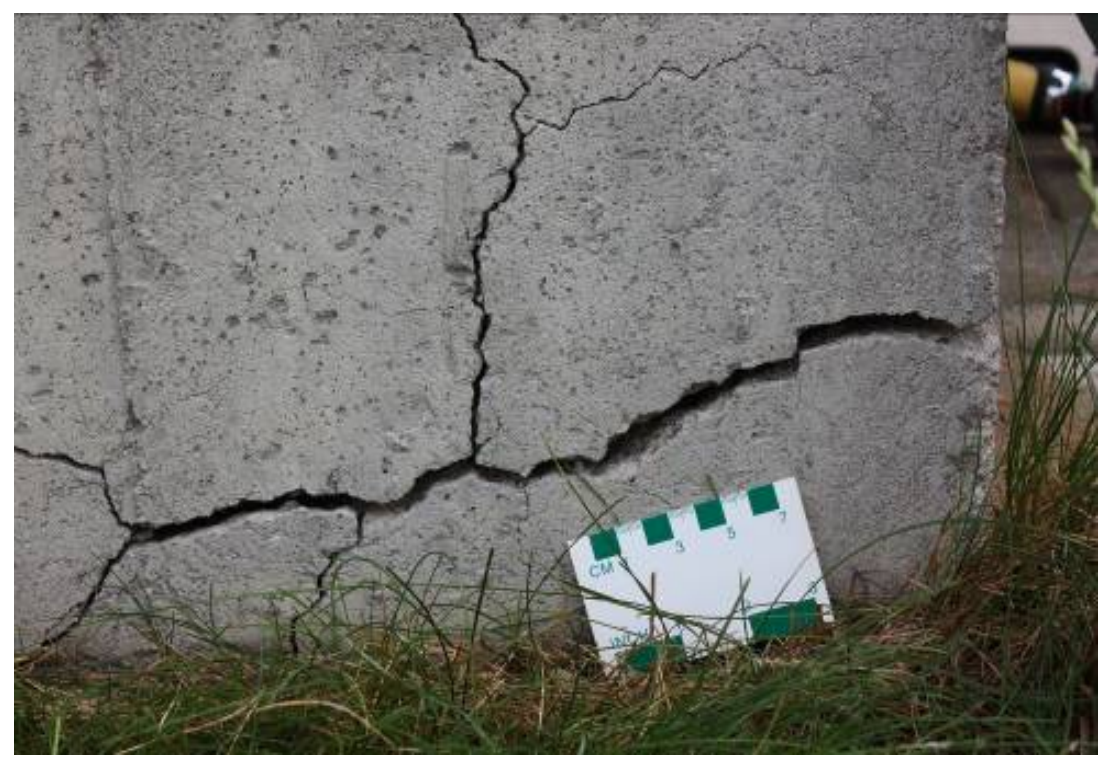

Fig. 1 Cracking in house concrete foundation.

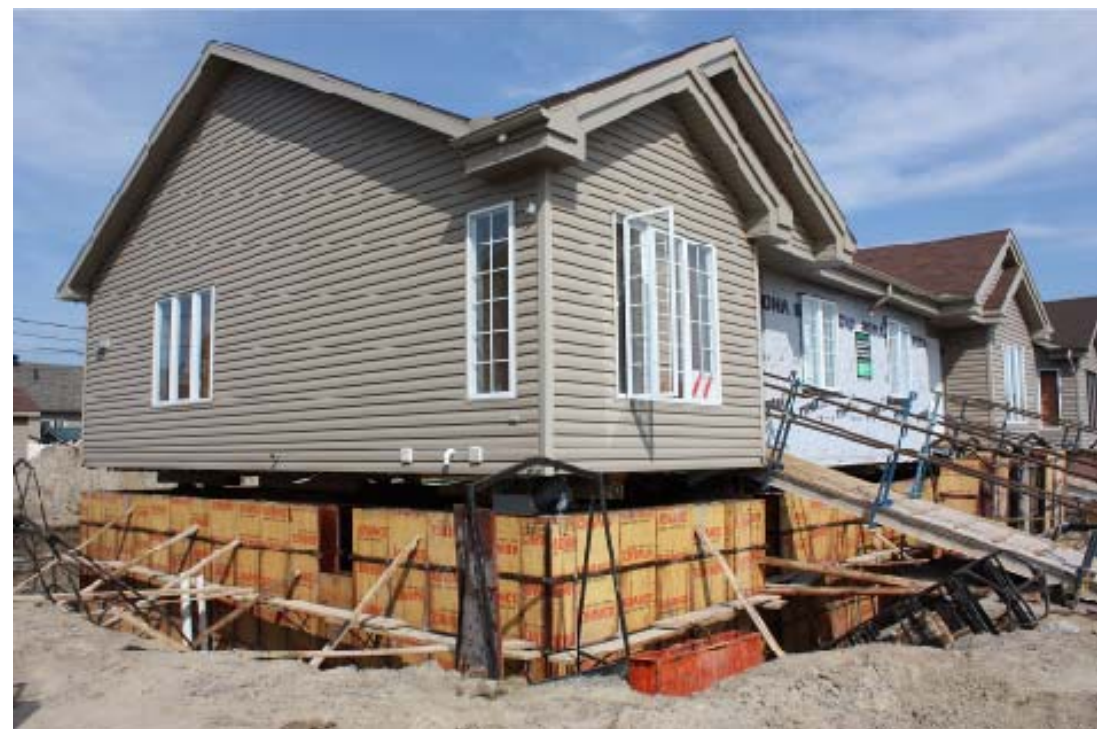

Fig. 2 Replacement of the concrete foundation walls. 


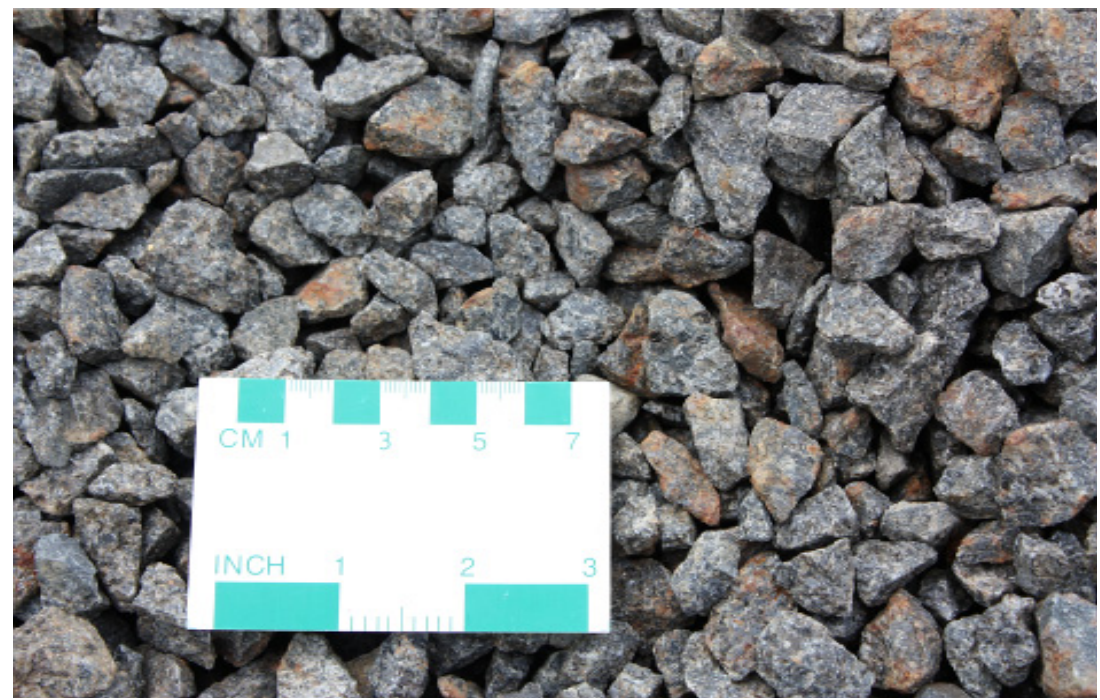

Fig. 3 Crushed coarse aggregate (anothositic gabbro).

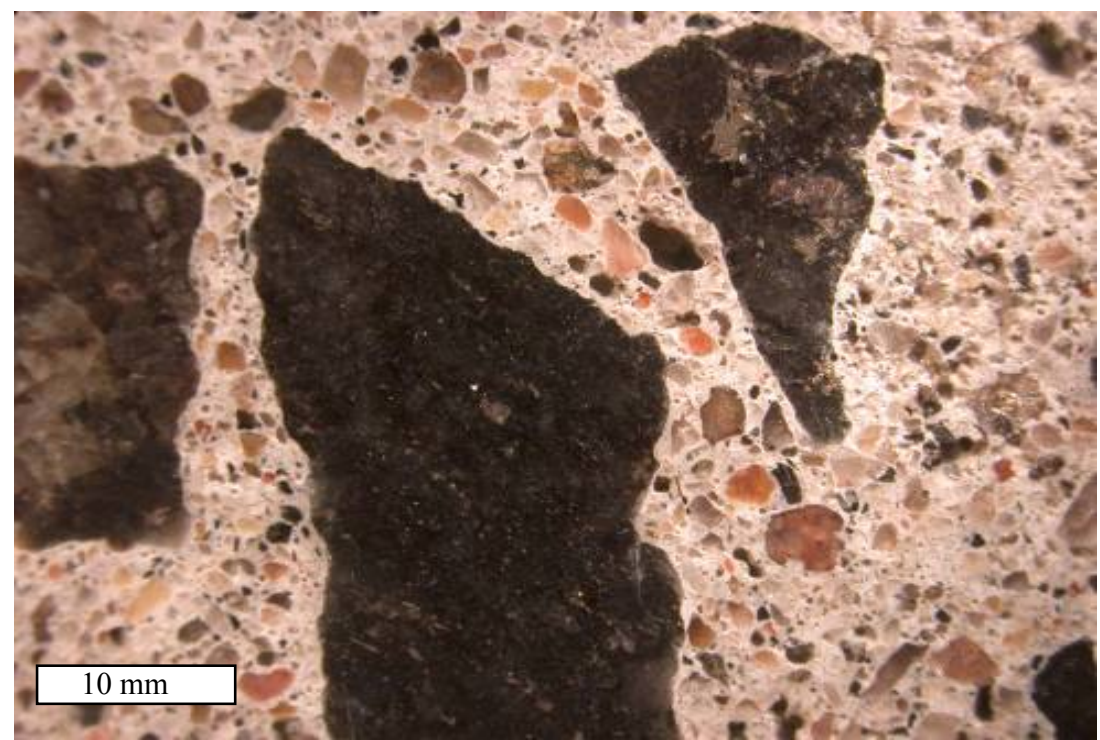

Fig. 4 Stereomicroscopic view of the anorthositic gabbro aggregate.
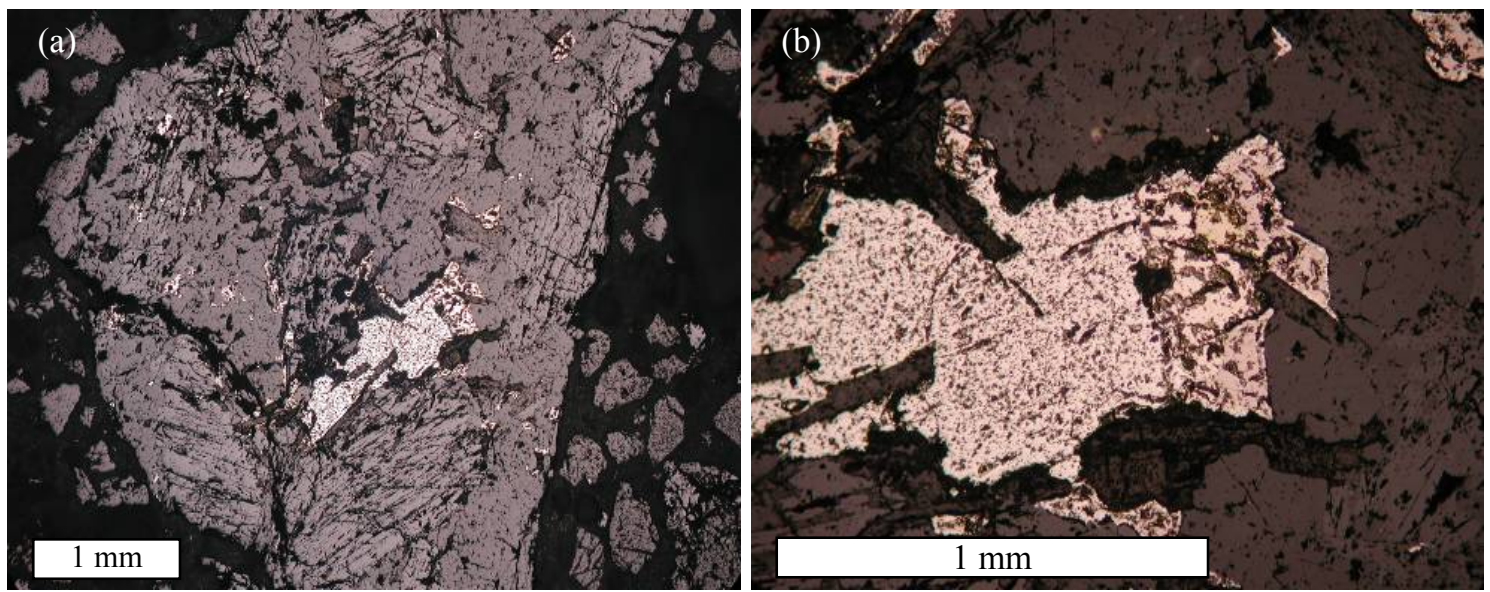

Fig. 5 Reflected polarized light views of iron sulphide minerals $(\mathrm{Py}=$ pyrite; $\mathrm{Po}=$ pyrrhotite $)$. 
pyrrhotite, were in close contact and well disseminated into silicate minerals. Very fine inclusion of opaque minerals can be seen throughout silicates. The observation of polished concrete samples confirms, in several cases, that the pyrite was intact while the pyrrhotite presented evident signs of oxidation.

Fig. 6 presents BSE (back-scattered electron) images of the sulphide minerals taken by EPMA. Pyrite and pyrrhotite are seen in close contact with each other. Pyrrhotite grains appear with a lighter color than pyrite on the BSE image due to its higher atomic density, with iron content higher and sulphur content lower than for pyrite.

Fig. 7 presents a large grain of pyrrhotite with small inclusions of pentlandite which appear whiter compared to pyrrhotite in BSE image due to their high atomic density. Both minerals showed extended cracking. Black areas in the BSE images correspond to resin or light silicates. Few flame-textured pentlandite exsolved in pyrrhotite can be seen close to grain boundary or along main cracks. Pentlandite is by

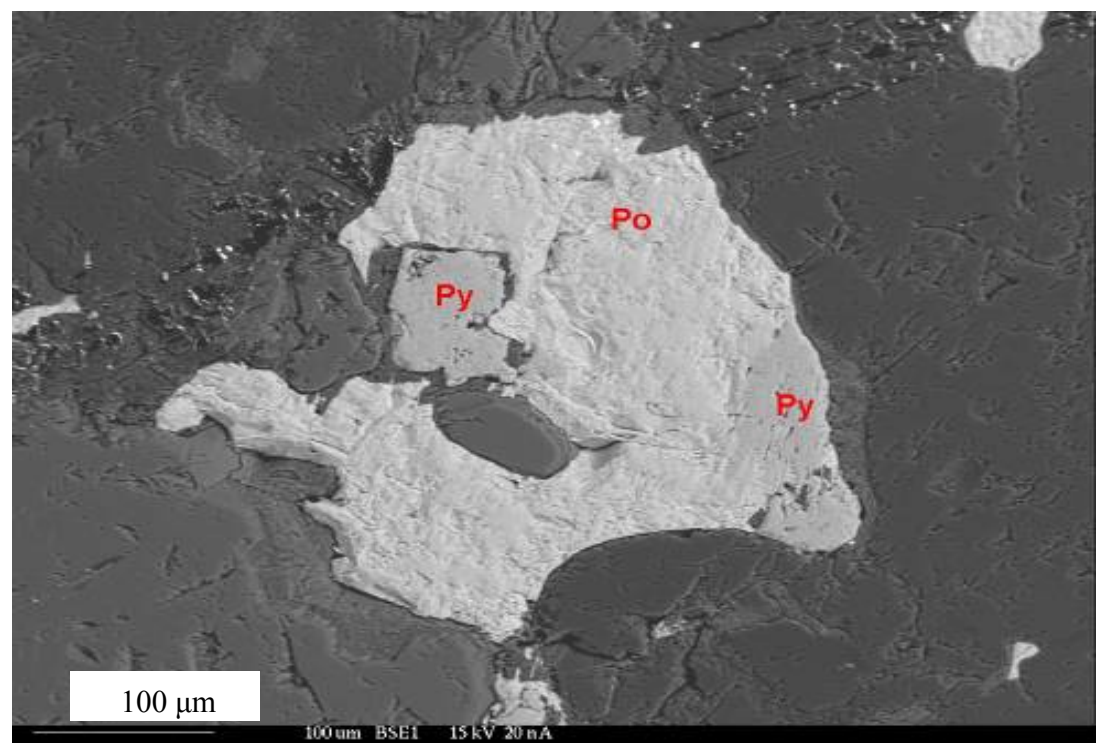

Fig. 6 Back-scattered electron images of sulphides minerals within the anorthositic gabbro $(\mathrm{Py}=$ pyrite; Po = pyrrhotite).

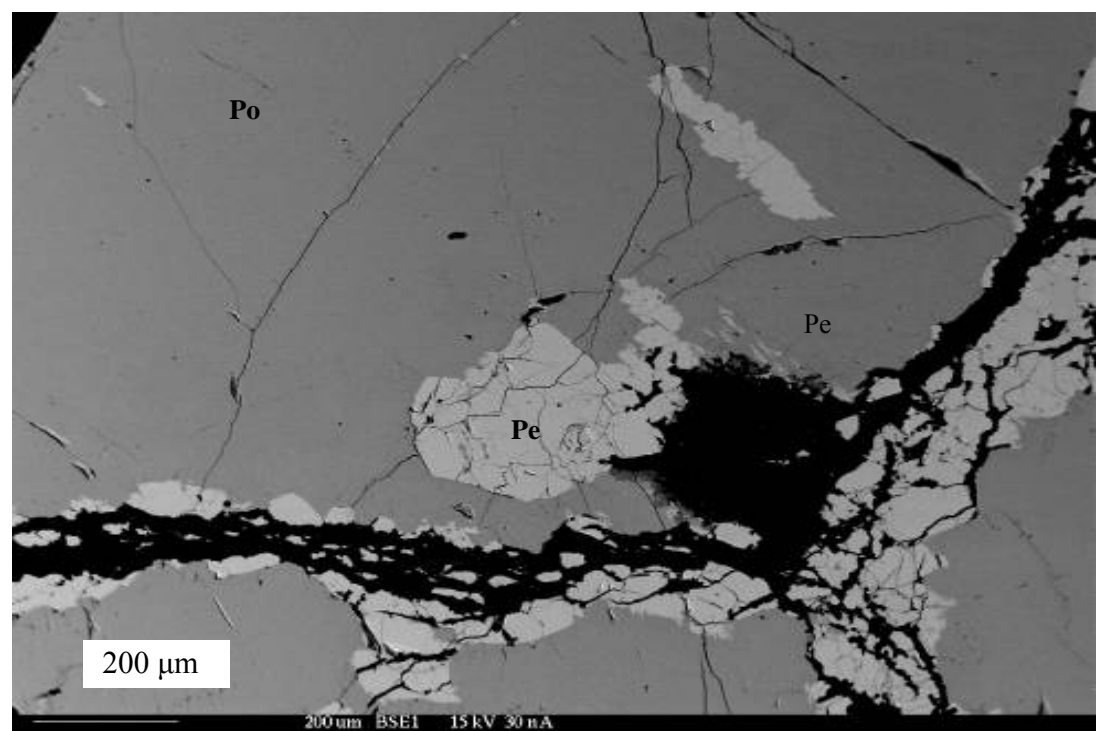

Fig. 7 Back-scattered electron images of a pyrrhotite grain with pentlandite inclusions gabbro $($ Po $=$ pyrrhotite; $P e=$ pentlandite). 
Table 1 Electron probe micro-analysis results measured on pyrrhotite (Po), pyrite (Py) and pentlandite (Pe) grains, results are presented in weight percents.

\begin{tabular}{lllllllc}
\hline & $\mathrm{S}$ & $\mathrm{Cu}$ & $\mathrm{Ni}$ & $\mathrm{Fe}$ & $\mathrm{Co}$ & $\mathrm{As}$ & Total \\
\hline Po-1 & 38.456 & 0.004 & 0.588 & 59.717 & 0.180 & 0.000 & 98.945 \\
Po-2 & 38.693 & 0.000 & 0.503 & 59.020 & 0.255 & 0.011 & 98.482 \\
Po-3 & 37.957 & 0.029 & 0.681 & 59.368 & 0.104 & 0.000 & 98.139 \\
Po-4 & 38.052 & 0.021 & 0.674 & 59.225 & 0.303 & 0.000 & 98.275 \\
Po-5 & 38.008 & 0.039 & 0.688 & 59.365 & 0.000 & 0.051 & 98.151 \\
Po-6 & 38.644 & 0.008 & 0.363 & 59.631 & 0.000 & 0.015 & 98.661 \\
Mean-Po & 38.302 & 0.017 & 0.583 & 59.388 & 0.140 & 0.013 & 98.442 \\
Py-1 & 52.708 & 0.002 & 0.015 & 47.565 & 0.000 & 0.029 & 100.319 \\
Py-2 & 52.821 & 0.000 & 0.000 & 47.720 & 0.000 & 0.021 & 100.562 \\
Py-3 & 52.685 & 0.000 & 0.000 & 47.129 & 0.000 & 0.032 & 99.846 \\
Py-4 & 52.554 & 0.023 & 0.000 & 47.993 & 0.000 & 0.013 & 100.583 \\
Py-5 & 52.570 & 0.000 & 0.000 & 47.338 & 0.029 & 0.030 & 99.967 \\
Py-6 & 52.580 & 0.000 & 0.000 & 47.082 & 0.134 & 0.051 & 99.847 \\
Mean-Py & 52.653 & 0.004 & 0.003 & 47.471 & 0.027 & 0.029 & 100.187 \\
Pe- 1 & 32.750 & 0.000 & 35.139 & 28.968 & 3.548 & 0.007 & 100.412 \\
Pe -2 & 32.646 & 0.000 & 35.394 & 28.700 & 3.400 & 0.040 & 100.180 \\
Mean-Pe & 32.698 & 0.000 & 35.267 & 28.834 & 3.474 & 0.024 & 100.296
\end{tabular}

Pyrrhotite $\mathrm{Fe}_{1-\mathrm{x}} \mathrm{S}$ where $x=0.099$

far more cracked than pyrrhotite.

Table 1 presents quantitative microanalysis determined by EPMA punctual mode on sulphide minerals. According to EPMA analysis, pyrrhotite contains small amount of $\mathrm{Ni}, \mathrm{Co}, \mathrm{Cu}$ and As substituting for Fe in the mineral structure. Analyses are consistent and showed little variations between the different grains analysed. Considering element substitution, $x$ value in the chemical formula of pyrrhotite $\left(\mathrm{Fe}_{1-\mathrm{x}} \mathrm{S}\right)$ was calculated to 0.099. Pyrite contains only very small amount of $\mathrm{Co}$ and As while content up to $3.47 \%$ Co was measured in the pentlandite.

Fig. 8 presents stereomicroscopic views of the deteriorated concrete. In general, the cement paste is highly porous. This is not surprising considering the minimum compressive strength of $15 \mathrm{MPa}$ required for plain concrete used in residential foundation applications. High water-cement ratio in the order of 0.7 is often used for this application. Most of the concrete samples were highly damaged, with important cracking being observed around or through the aggregate particles and the cement pastes. The bond between the aggregate particles and the cement paste is very weak and some concrete samples can be easily broken in pieces by hand. They were often too damaged to be polished.

Some aggregate particles were extensively cracked, with some cracks extending from the aggregate particles to the surrounding cement paste (Figs. 8a and 8c). Most of the time, cracking occurred next to sulphide rich particles. Sometime, aggregate particles were mostly debonded, as in Figs. 8b and 8c and some particles were completely disintegrated. Fig. $8 \mathrm{~d}$ is an enlargement showing rust (iron oxyhydroxide/iron sulphate) and a whitish powdery secondary product close to an air void.

Results obtained from stereomicroscopic examinations confirm that the pyrrhotite grains were mainly oxidized while pyrite grains were intact. The nature/composition of the secondary reaction products observed during stereomicroscopic examination was determined by SEM observations.

Fig. 9 shows a pyrrhotite grain on the left end side 

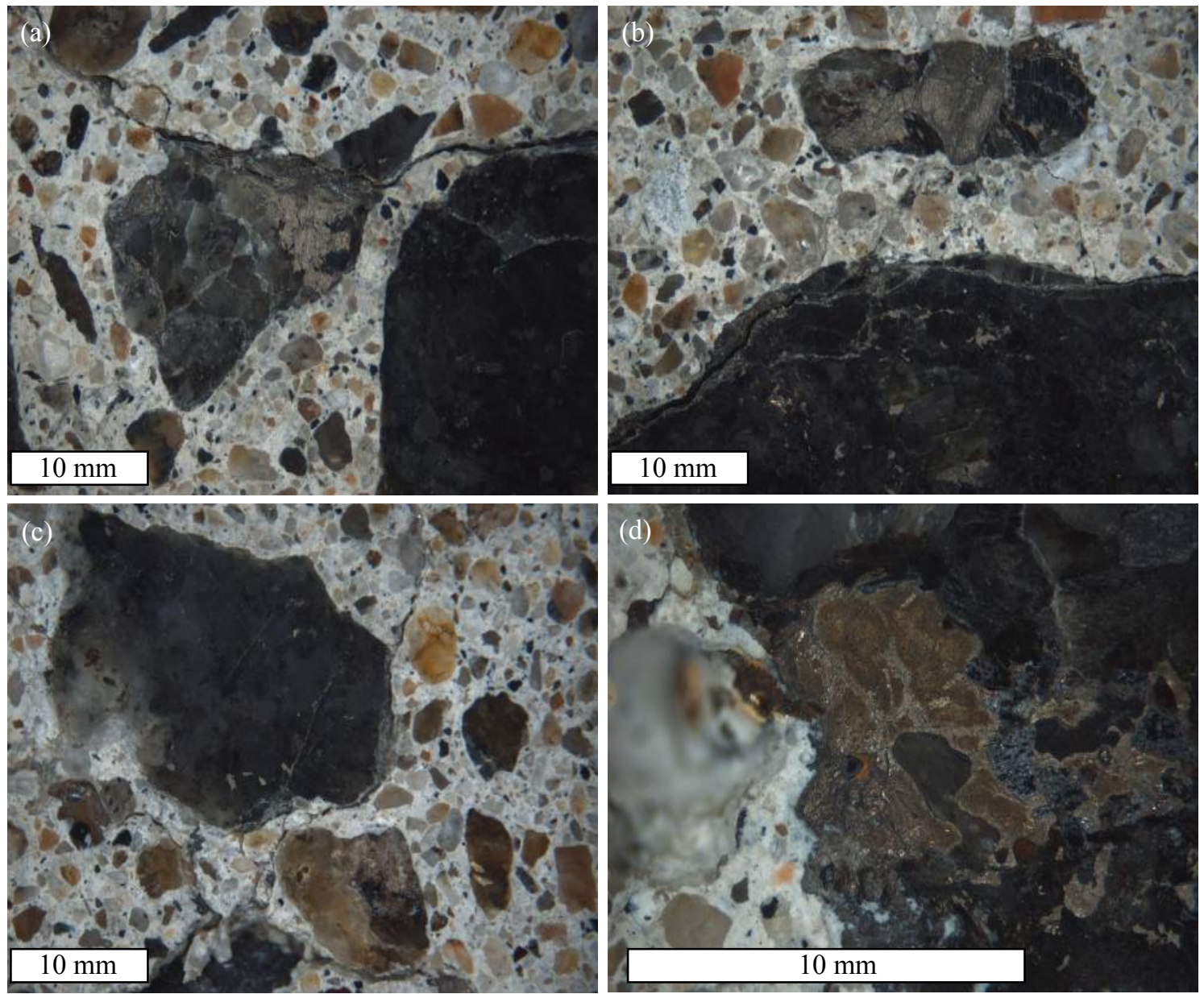

Fig. 8 Stereomicroscopic views of deteriorated concretes.

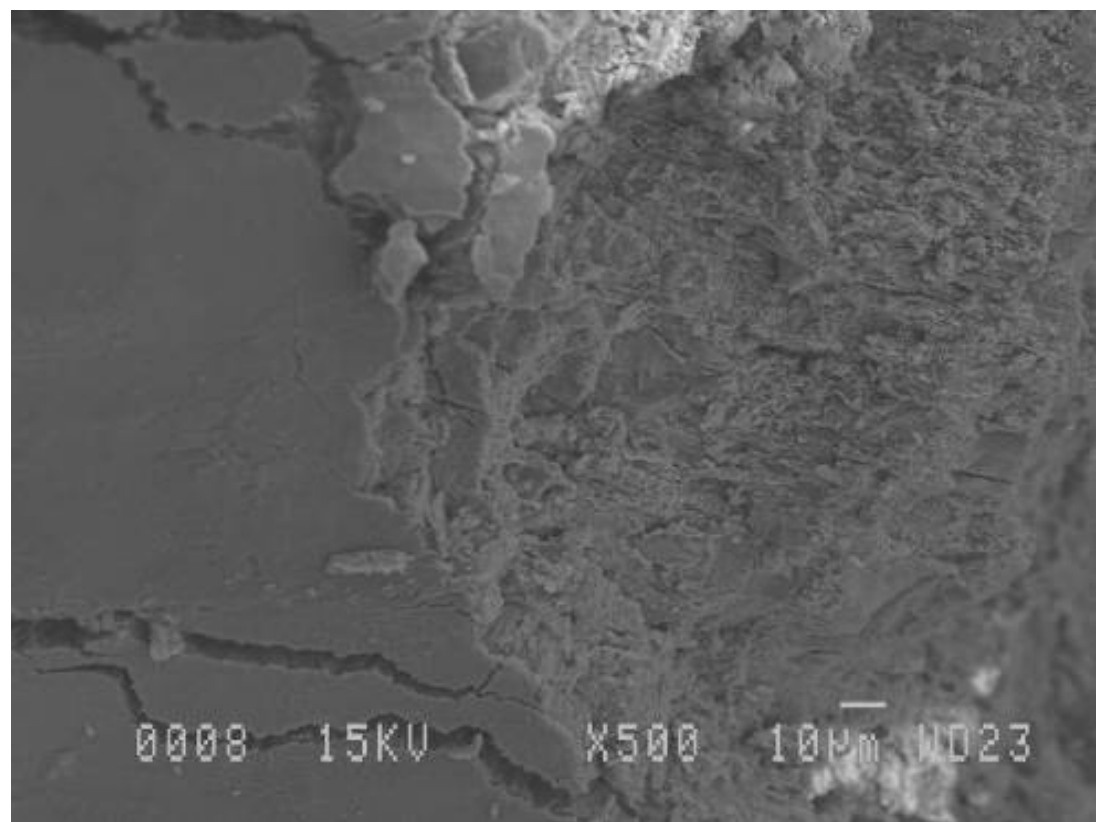

Fig. 9 SEM images of deteriorated concrete with a pyrrhotite grain (left)in contact with iron oxyhydroxide (right). 


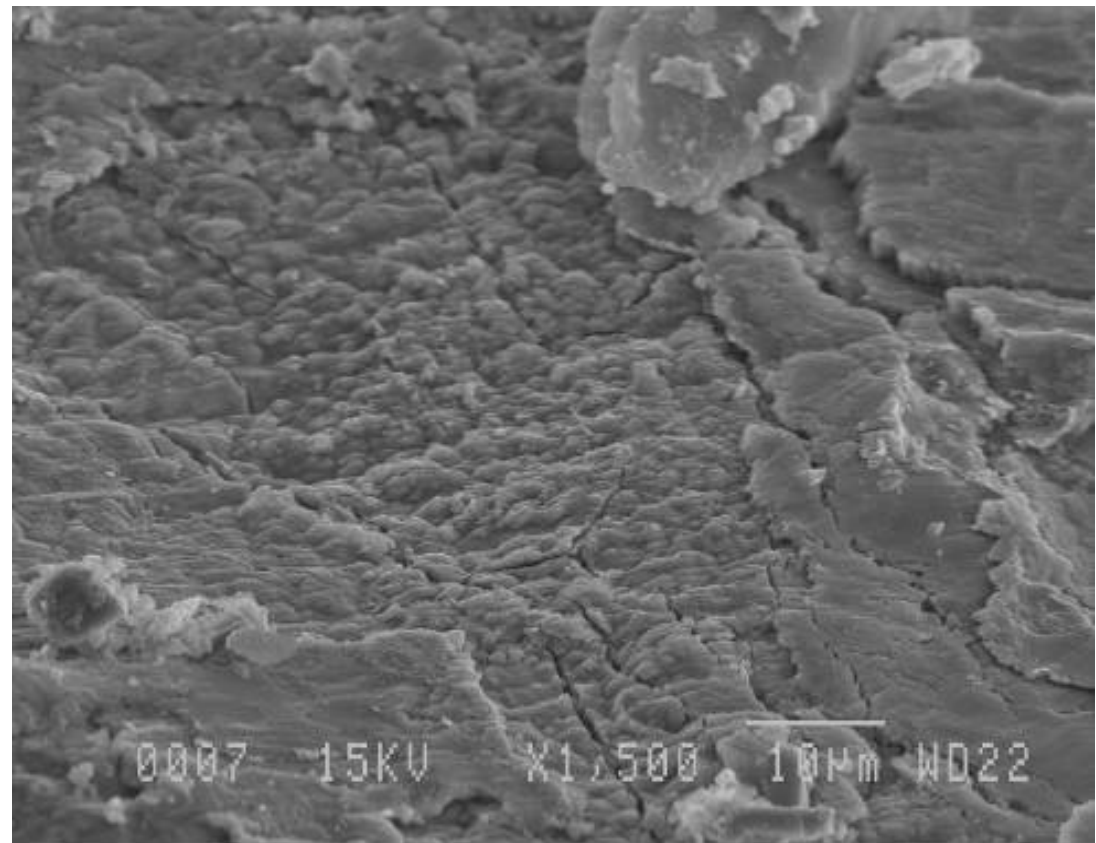

Fig. 10 SEM images of deteriorated concrete with iron sulphate close to pyrrhotite grain.
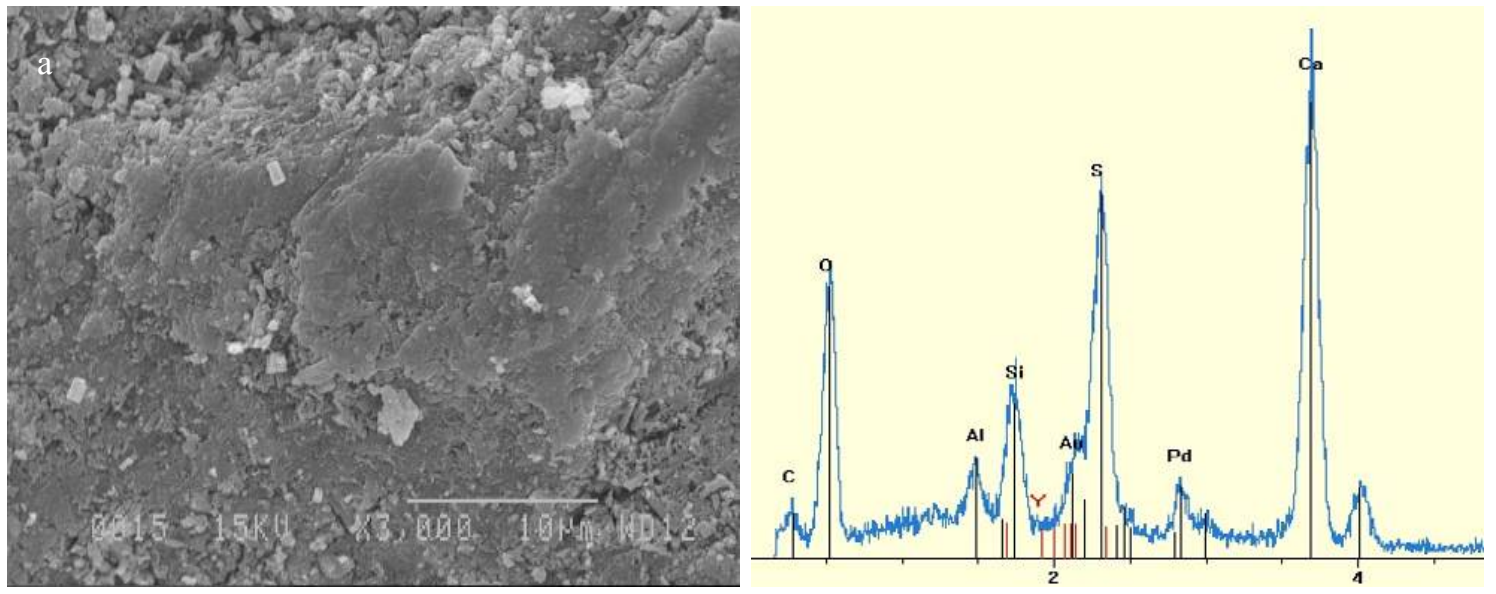

Fig. 11 SEM images + EDXA analysis of gypsum present in deteriorated concrete.

of the micrograph, in close contact with an iron oxide, hydroxide or oxyhydroxide. The precise nature of the oxidation product can not be determined using EDXA because hydrogen is not detected. The EDXA signal (not presented) shows the x-ray lines of iron (Fe) and oxygen (O). Fig. 10 shows a layer of an iron sulphate next to a pyrrhotite grain. The EDXA signal shows the $\mathrm{x}$-ray lines of iron $(\mathrm{Fe})$, sulphur $(\mathrm{S})$ and oxygen $(\mathrm{O})$ (not presented). These secondary products are associated to the reaction of pyrrhotite. Fig. 11 exhibits a grain of gypsum (calcium sulphate dehydrate) with corresponding EDAX spectrum. SEM observations have confirmed the identification of secondary minerals/phases, mostly iron oxide, hydroxide or oxyhydroxide, iron sulphate and gypsum near altered pyrrhotite grains.

\section{Discussion}

Based on petrographic examination, pyrrhotite was determined as the deleterious mineral phase in the concrete samples. It is well-known in the mining environment literature that sulphide minerals are unstable in oxidizing conditions. Upon exposure to water and oxygen, sulphide minerals oxidize to form 
acidic, iron and sulphate-rich by-products according to the following equations [5]:

$$
\begin{gathered}
\mathrm{Fe}_{1-\mathrm{x}} \mathrm{S}+(2-\mathrm{x} / 2) \mathrm{O}_{2}+\mathrm{xH}_{2} \mathrm{O} \rightarrow \\
(1-\mathrm{x}) \mathrm{Fe}^{2+}+\mathrm{SO}_{4}{ }^{2-}+2 \mathrm{x} \mathrm{H}^{+}
\end{gathered}
$$

The oxidation of ferrous iron $\left(\mathrm{Fe}^{2+}\right)$ produces ferric ions $\left(\mathrm{Fe}^{3+}\right)$ that can precipitate out of solution to form ferric hydroxide, if $\mathrm{pH}$ is not too low. $\mathrm{Fe}^{2+}$ is oxidized and precipitated as ferric oxyhydroxides, principally ferrihydrite and goethite.

$$
\begin{gathered}
\mathrm{Fe}^{2+}+1 / 4 \mathrm{O}_{2}+2 \mathrm{H}^{+} \rightarrow \mathrm{Fe}^{3+}+1 / 2 \mathrm{H}_{2} \mathrm{O} \\
\mathrm{Fe}^{3+}+3 \mathrm{H}_{2} \mathrm{O} \rightarrow \mathrm{Fe}(\mathrm{OH})_{3(\mathrm{~s})}+3 \mathrm{H}^{+}
\end{gathered}
$$

The oxidation reaction of iron sulphides occurs only in the presence of oxygen and of humidity and generates various mineralogical phases [5-7]. According to Grattan-Bellew and Eden [8] and Shayan [9], the sulphuric acid generated through this process reacts with the solids of the cement paste, and particularly with the portlandite $\left(\mathrm{Ca}(\mathrm{OH})_{2}\right)$, to form gypsum according to the following equation:

$$
\mathrm{H}_{2} \mathrm{SO}_{4}+\mathrm{Ca}(\mathrm{OH})_{2} \rightarrow \mathrm{CaSO}_{4} \cdot 2 \mathrm{H}_{2} \mathrm{O} \text { (gypsum) }
$$

The attack of concrete by sulphates resulting from the oxidation of sulphide-bearing aggregates would produce the crystallization of secondary ettringite following the reaction with the alumina-bearing phases of the hydrated portland cement paste (Eq. (5)). According to Divet et al. [10], high $\mathrm{pH}$ conditions, as those found in concrete, enhance iron sulphide oxidation.

$$
\begin{aligned}
& 3\left(\mathrm{CaSO}_{4} \cdot 2 \mathrm{H}_{2} \mathrm{O}\right)+\mathrm{C}_{3} \mathrm{~A}+26 \mathrm{H}_{2} \mathrm{O} \rightarrow \\
& \mathrm{C}_{3} \mathrm{~A} \cdot 3 \mathrm{CaSO}_{4} \cdot \mathrm{H}_{32} \text { (ettringite) }
\end{aligned} \rightarrow
$$

In a general way, secondary products most frequently generated during the oxidation of iron sulphides are the "rust" under all its forms (goethite $(\mathrm{FeOOH})$, limonite $\left.\left(\mathrm{FeO}(\mathrm{OH}) \mathrm{nH}_{2} \mathrm{O}\right)\right)$, sulphates including gypsum and ettringite. Degradation of concrete is thus due to the combined mechanisms of oxidation of iron sulphides followed by sulphatation in the cement paste. Both reactions create secondary minerals that cause expansion. According to Casanova et al. 1996 [11], the later is by far more expansive. In fact, during the formation of gypsum, the volume of the resulting products represents a little more of double of that of the starting solids.

According to the scientific literature, the cases of deterioration of the concrete due to the oxidation of sulphide minerals were reported for porous and mechanically weak rocks such as black shale [11-14]. In the present case, the aggregate is an anorthosic gabbro with low porosity and despite its good mechanical performances, major damages were noticed only two to four years after construction. As mentioned before, the presence of oxygen and water is necessary for the oxidation reaction. Conditions were favourable for sulphide oxidation and it is possible that presence of other sulphide minerals (pyrite, pentlandite, chalcopyrite) can have played a role of catalyst increasing the kinetic of pyrrhotite reaction. The role or synergy of other sulphide minerals should be investigated.

\section{Conclusions}

Cases of degradation of concrete associated to iron sulphides-bearing aggregates were recently recognized in the Trois-Rivières area, Canada. This study reports result of site inspection along with concrete cores characterisation using different petrographic tools including stereomicroscope, polarizing microscope, SEM and EPMA. Main results show that:

- Deteriorated concrete display map cracking, yellowish coloration, open cracks more pronounced at the corners of the foundation often next to drainage elements;

- The problematic aggregate is an anorthositic gabbro containing iron sulphide minerals;

- Iron sulphides are finely disseminated into silicate minerals;

- Pyrrhotite is oxidized while pyrite is not, the former contains $\mathrm{Ni}, \mathrm{Co}, \mathrm{Cu}$ and As substituting for $\mathrm{Fe}$;

- Considering element substitution, $x$ value in the non-stoichiometric mineral chemical formula $\left(\mathrm{Fe}_{1-\mathrm{x}} \mathrm{S}\right)$ was calculated to 0.099 in the pyrrhotite studied; 
- Concrete samples are highly damaged, with important cracking observed around and through the aggregate particles and the cement paste, and some particles completely disintegrated or debonded;

- Secondary minerals identified are iron oxide/hydroxide/oxyhydroxyde, iron sulphate and gypsum;

- The oxidation of pyrrhotite followed by sulphatation of the cement paste seems to be the main mechanism of concrete deterioration.

Further research is needed to develop a quality control test to identify potentially deleterious aggregates.

\section{Acknowledgments}

This study has been supported by the National Science and Engineering Research Council of Canada (NSERC) and by the Fonds de recherche sur la nature et les technologies of the Province of Québec (FQRNT).

\section{References}

[1] J.P.R. de Villiers, D.C. Liles, The crystal-structure and vacancy distribution in 6C pyrrhotite, American Mineralogist 95 (2010) 148-152.

[2] D.C. Liles, J.P.R. de Villiers, Redetermination of the structure of 5C pyrrhotite at low temperature and at room temperature, American Mineralogist 97 (2012) 257-261.

[3] M. Becker, J. de Villiers, D. Bradshaw, The mineralogy and crystallography of pyrrhotite from selected nickel and PGE ore deposits, Economic Geology 105 (2010) 1025-1037.

[4] D. Jana, Sample preparation techniques in petrographic examinations of construction materials: A state-of-the-art review, in: ICMA Conference Proceedings of the 28th Conference on Cement Microscopy, Denver, USA, 2006, pp. 23-70.

[5] N. Belzile, Y.W. Chen, M.F. Cai, Y. Li, A review on pyrrhotite oxidation, Journal of Geochemical Exploration 84 (2004) 65-76.

[6] Y.L. Mikhlin, A.V. Kuklinskiy, N.I. Pavlenko, V.A. Varnek, I.P. Asanov, A.V. Okotrub, et al., Spectroscopy and XRD studies of the air degradation of acid-reacted pyrrhotites, Geochimica and Cosmochimica Acta 66 (2002) 4057-4067.

[7] H.F. Steger, Oxidation of sulphide minerals: VII, Effect of temperature and relative humidity on the oxidation of pyrrhotite, Chemical Geology 35 (1982) 281-295.

[8] P.E. Grattan-Bellew, W.J. Eden, Concrete deterioration and floor heave due to biogeochemical weathering of underlying shale, Canadian Geotechnical Journal 12 (1975) 372-378.

[9] A. Shayan, Deterioration of a concrete surface due to the oxidation of pyrite contained in pyritic aggregates, Cement and Concrete Research 18 (1988) 723-730.

[10] L. Divet, J.P. Davy, Study of pyrite oxidation risk in the basic medium of concrete, LCPC Bulletin 204 (1996) 97-107. (in French)

[11] I. Casanova, L. Agullo, A. Aguado, Aggregate expansivity due to sulphide oxidation-I. Reaction system and rate model, Cement and Concrete Research 26 (1996) 993-998.

[12] J. Berard, R. Roux, M. Durand, Performance of concrete containing a variety of black shale, Canadian Journal of Civil Engineering 2 (1975) 58-65.

[13] J.S. Chinchon, C. Ayora, A. Aguado, F. Guirado, Influence of weathering of iron sulfides contained in aggregates on concrete durability, Cement and Concrete Research 25 (1995) 1264-1272.

[14] C. Ayora, S. Chinchon, A. Aguado, F. Guirada, Weathering of iron sulfides and concrete alteration, Cement and Concrete Research 28 (4) (1998) 1223-1235. 